\title{
Solute Clusters/Enrichment at the Early Stage of Ageing in Mg-Zn-Gd Alloys Studied by Atom Probe Tomography
}

\author{
Xin-Fu Gu ${ }^{1,2} \cdot$ Tadashi Furuhara ${ }^{2} \cdot$ Leng Chen ${ }^{1} \cdot$ Ping Yang ${ }^{1}$ \\ Received: 31 July 2018/Revised: 3 September 2018/Published online: 1 November 2018 \\ (C) The Chinese Society for Metals and Springer-Verlag GmbH Germany, part of Springer Nature 2018
}

\begin{abstract}
Three-dimensional distribution of solute elements in an $\mathrm{Mg}-\mathrm{Zn}-\mathrm{Gd}$ alloy during ageing process is quantitatively characterized by three-dimensional atom probe (3DAP) tomography. Based on the radius distribution function, it is found that $\mathrm{Zn}-\mathrm{Gd}$ solute pairs in Mg matrix appear mainly at two peaks at early stage of ageing, and the separation distance between $\mathrm{Zn}$ and Gd atoms could be well rationalized by the first-principle calculation. Moreover, the fraction of $\mathrm{Zn}-\mathrm{Gd}$ solute pairs increases first and then decreases due to the precipitation of long-period stacking ordered (LPSO) structures. Both the composition of the structural unit in LPSO structure and the solute enrichment around it are quantified. It is found that $\mathrm{Zn}$ and Gd elements are synchronized in the LPSO structure, and solute segregation of pure $\mathrm{Zn}$ or Gd is not observed at the transformation front of the LPSO structure in this alloy. In addition, the crystallography of transformation front is further determined by 3DAP data.
\end{abstract}

Keywords Magnesium alloy · Long-period stacking ordered (LPSO) - Atomic cluster · Three-dimensional atom probe (3DAP) · Crystallography

\section{Introduction}

Magnesium alloys are known as the lightest metallic materials for structural application and thus are attractive to the applications in transport system to save the energy consumption by reducing the body weight. However, their applications are limited by their relative low mechanical properties at both room and elevated temperatures and poor corrosion resistance [1]. Recently, a new promising strengthening phase, namely long-period stacking ordered (LPSO) structure, has been found in $\mathrm{Mg}-\mathrm{Zn}-\mathrm{Y}$ and $\mathrm{Mg}-$ $\mathrm{Zn}-\mathrm{Gd}$ alloys [2-9]. Similar LPSO structures could be also found in $\mathrm{Mg}-M-\mathrm{RE}(M$ : $\mathrm{Zn}, \mathrm{Al}, \mathrm{Cu}, \mathrm{Ni}$, or $\mathrm{Co}, \mathrm{RE}: \mathrm{Y}, \mathrm{Gd}$, Tb, Dy, Ho, Er, Tm) alloy systems [10-15].

Available online at http://link.springer.com/journal/40195

Xin-Fu Gu

xinfugu@ustb.edu.cn

1 School of Materials Science and Engineering, University of Science and Technology Beijing, Beijing 100083, China

2 Institute for Materials Research, Tohoku University, Sendai 980-8577, Japan
As shown in Fig. 1a, b, the LPSO structure has a lamellar structure paralleling to $(0001)_{\alpha}$ basal plane, within which four-layer-height fcc structural units (SU for short hereafter, and ABCA stacking ordered SU is highlighted by grey colour in Fig. 1) are separated by several Mg layers (hcp structure) depending on the specific structures [15-18]. The hcp structure of Mg matrix could be transformed into fcc SU by gliding of a $\langle 10-10\rangle_{\alpha} / 3$ partial dislocation as schematically shown in Fig. 1c. Commonly observed LPSO structures $10 \mathrm{H}, 18 \mathrm{R}, 14 \mathrm{H}$, and $24 \mathrm{R}$ correspond to the intermediate $\mathrm{Mg}$ layers of $1,2,3$, and 4, respectively [17, 18], where the symbols for the LPSO structures are based on Ramsdell's notation. The SUs in the LPSO structure usually synchronize with chemical order/ enrichment of RE and $M$ [19-21], and further, it is proposed to contain ordered distributed $M_{6} \mathrm{RE}_{8}$ clusters with $\mathrm{L}_{2}$ type structure $[13,20]$. The composition of LPSO structures locates around a line with a $M: \mathrm{RE}$ ratio equal to $3: 4$ in ternary phase diagram due to the $M_{6} \mathrm{RE}_{8}$ clusters in $\mathrm{SU}$; thus, theoretical composition for 14H LPSO structure is deduced to be $\mathrm{Mg}_{35} M_{3} \mathrm{RE}_{4}[20,22]$; however, the measured composition is often lower than the theoretical value $[13,20]$. The inconsistency could be explained by the existence of domain structures of $\mathrm{L}_{2}$ clusters in the SU/ 


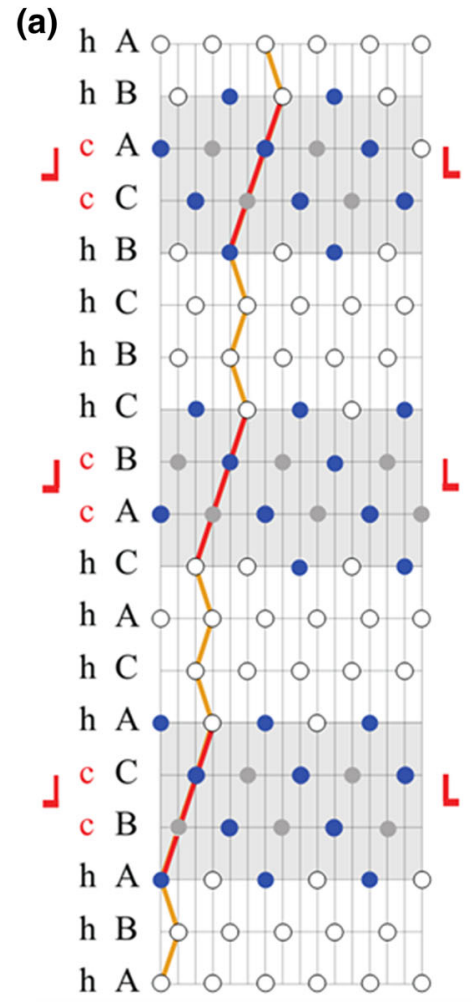

$18 \mathrm{R}$
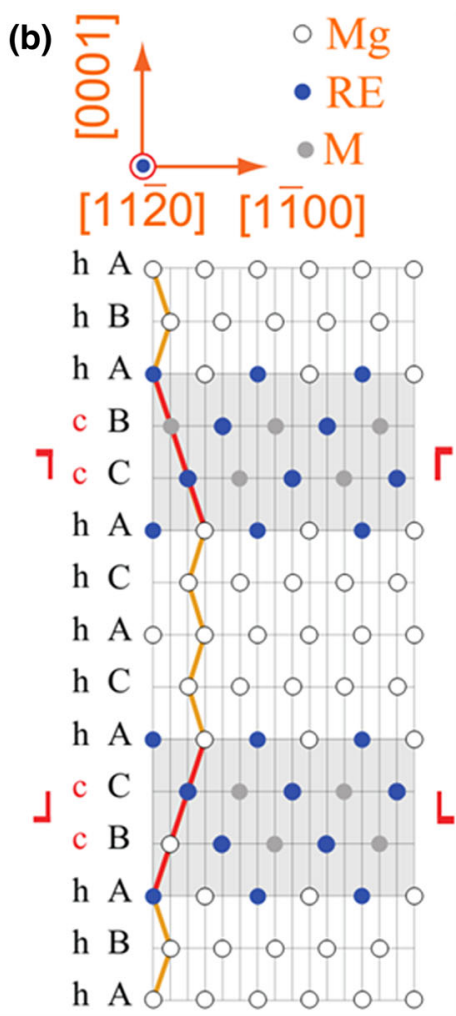

$14 \mathrm{H}$ (c)

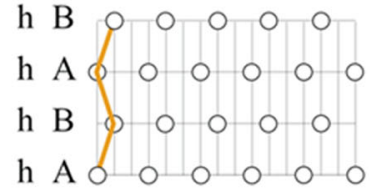

HCP

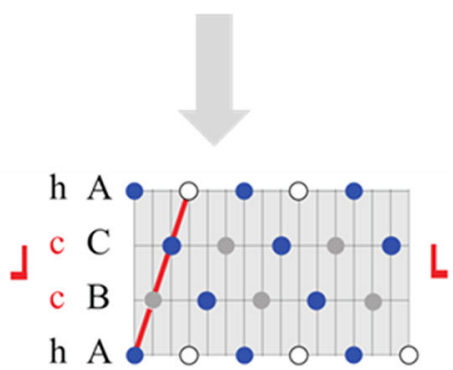

FCC structure unit (SU)

Fig. $1\langle 11-20\rangle_{\alpha}$ view of typical LPSO structures: a 18R, b $14 \mathrm{H}$, c the transformation from hcp structure to fcc SU. The fcc SUs in a-b are highlighted by grey box. The transformation of hcp structure to fcc needs two processes. One is the stacking sequence change by the movement of a partial dislocation, and the other is segregation of $\mathrm{RE}$ and $M$ solute atoms to SU

LPSO structures [23-25]. Compared to the crystal structure of LPSO structures, the understanding of transformation mechanism of LPSO structure in crystalline $\mathrm{Mg}$ matrix is still unsatisfied [26-29].

The LPSO structure in $\mathrm{Mg}-M-\mathrm{RE}$ alloy is divided into two types depending on the formation process [8, 10]. If the LPSO phase is formed during casting procedure, the alloy is classified as Type I alloy, and if the LPSO phase is only generated by subsequent heat treatment after casting, the alloy is defined as Type II alloy. Likubo et al. [30] show that these differences can be attributed to the different spinodal decomposition temperature according to the thermodynamic calculation, and Type II alloy has a lower decomposition temperature compared to Type I alloy. With a lower spinodal decomposition temperature, the diffusivity of atoms is not high enough for the transformation; thus, LPSO transformation could not be found in the Type II alloy in as-cast condition. Nevertheless, the composition modulation in LPSO phase is believed to be attributed to the spinodal decomposition during solidification or the subsequent heat treatment.

Meanwhile, according to Fig. 1c, the formation of a SU needs both structural change and solute enrichment. Two mechanisms are possible for the formation of LPSO structure in crystalline $\mathrm{Mg}$ matrix [28, 29, 31], which is schematically shown in Fig. 2. The first mechanism is that the solute atoms often segregate to the dislocations, and this segregation will assist the nucleation of SU, i.e. the structural transformation from hep to fcc by dislocation dissociation as shown in Fig. 2a, since the segregation of solute atoms $M$ and RE could lower the stacking fault energy. The second mechanism is that the chemical modulation or cluster takes in the first place shown in Fig. 2b, and then, stacking fault forms, and this procedure is repeated for other SUs. Therefore, the cluster behaviour in $\mathrm{Mg}$ matrix is crucial to distinguish these two processes.

Experimentally, the co-segregation of $\mathrm{Zn}$ and $\mathrm{Y}$ atoms in $\mathrm{Mg}-\mathrm{Zn}-\mathrm{Y}$ (Type I) alloy, so-called Guinier-Preston (G.P.) zone, is observed by high-angle annular dark field (HAADF) scanning transmission electron microscopy (STEM) and STEM-EDS [32]. Similar results are found in Mg-Al-Gd (Type I) alloy [27, 31] and Mg-Zn-Gd (Type II) alloy [33]. These results may support the viewpoint of spinodal decomposition, since the segregation/enrichment in $\mathrm{Mg}$ matrix was observed. On the one hand, the observed solute enrichment is often planar type which is observable 
(a)
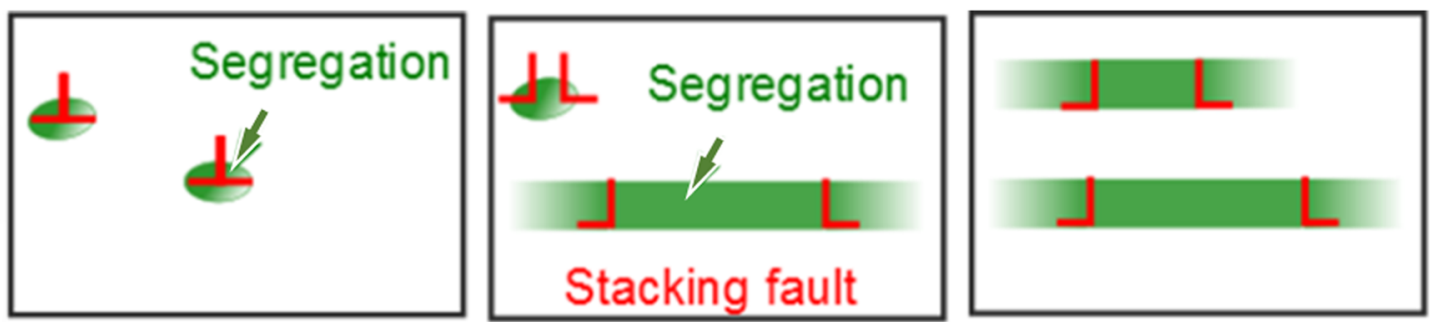

(b)
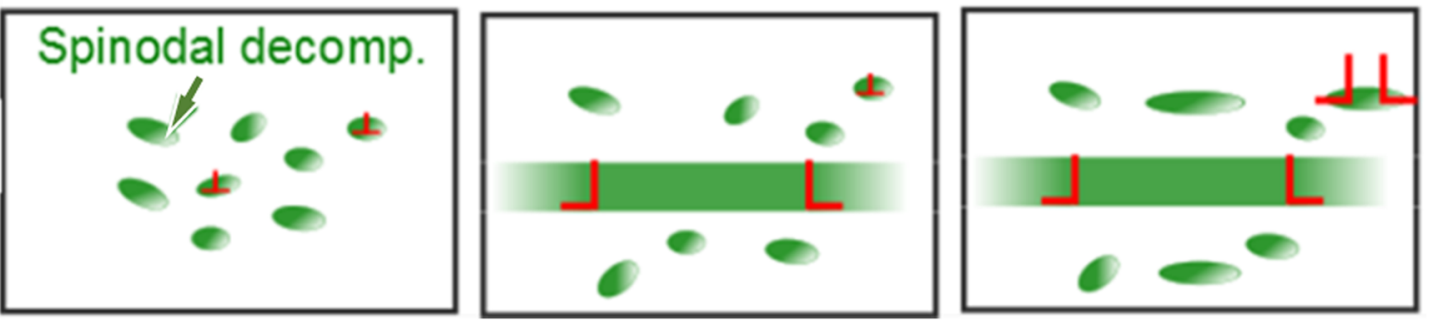

Fig. 2 Schematic diagram of two possible mechanisms for LPSO formation in crystalline Mg matrix: a element segregation-assisted dislocation dissociation, b chemical modulation/cluster forms first without structural change

by HAADF-STEM. On the other hand, three-dimensional distribution of the chemical modulation or solute cluster is not clear. The observation method based on HAADFSTEM cannot quantify the three-dimensional chemical information. Moreover, we recently proposed that the concentrated area is mainly Gd according to the experimental result by three-dimensional atom probe (3DAP) in $\mathrm{Mg}-\mathrm{Al}-\mathrm{Gd}$ (Type I) alloy, i.e. $\mathrm{Gd}$ and $\mathrm{Al}$ may be not synchronized during LPSO formation [27]. The situation in other alloy system, especially for early stage of LPSO formation, is unclear. Therefore, the cluster behaviour between solute atoms in early stage of ageing should be investigated.

3DAP tomography is a useful method to analyse the spatial distribution of the solute atoms in $\mathrm{Mg}$ alloy, and it has been used in analysing the cluster or precipitation in metallic materials, such as precipitates in $\mathrm{Mg}$ alloy [34, 35] and clusters in matrix [36-38]. In this study, the cluster behaviour during ageing of $\mathrm{Mg}_{97} \mathrm{Zn}_{1} \mathrm{Gd}_{2}$ alloy will be statistically investigated by 3DAP. However, Nie et al. [36] have observed $\mathrm{Zn}$ and $\mathrm{Gd}$ cluster tendency in an $\mathrm{Mg}-\mathrm{Zn}-$ Gd alloy, in which metastable $\gamma^{\prime \prime}$ phase is formed before the formation of SU $\left(\gamma^{\prime}\right)$. On the contrary, due to the different alloy composition in the present study, SU directly precipitates from the matrix without precursor phase.

\section{Experimental}

Since $\mathrm{Mg}_{97} \mathrm{Zn}_{1} \mathrm{Gd}_{2}$ alloy is a Type II alloy, little LPSO structure pre-exists in the as-cast sample. Moreover, ageing of the sample after solution treatment would precipitate precursor $\gamma^{\prime \prime}$ phase other than LPSO SU at such temperature [36, 39-41]. Thus, direct ageing of the as-cast sample is carried out at $280{ }^{\circ} \mathrm{C}$ for $15 \mathrm{~min}$ and $1 \mathrm{~h}$. In 3DAP technique, the atoms in the needle-like sample are evaporated one by one by the evaporation field due to curvature. The spatial resolution is anisotropic in the 3DAP technique, and the resolution along the needle axis is the best, which is smaller than $0.25 \mathrm{~nm}$ (spacing between basal planes). Therefore, in order to observe the chemical distribution within the LPSO structure, the needle axis should be closely paralleling to $(0001)_{\alpha}$ plane normal to reach the highest resolution. Therefore, we search for proper grains with the aid of electron backscatter diffraction (EBSD) system (TSL, EDAX). The procedure for preparing a 3DAP sample within Mg matrix is shown in Fig. 3a-f in order. Firstly, a grain with normal direction (ND) close to $(0001)_{\alpha}$ is selected by EBSD mapping. Then, the needle sample is cut and needled by focus ion beam (FIB) system equipped in a scanning electron microscope (SEM, Quanta 200, FEI). The 3DAP data are taken with CAMECA Leap $4000 \mathrm{HR}$ at $35 \mathrm{~K}$. A pulse fraction of $20 \%$ with pulse frequency of $200 \mathrm{kHz}$ is used. The cluster tendency in matrix is analysed by radius distribution function.

\section{Results and Discussion}

Figure $4 \mathrm{a}, \mathrm{b}$ shows the $3 \mathrm{DAP}$ results of as-cast sample and aged sample treated at $280{ }^{\circ} \mathrm{C}$ for $1 \mathrm{~h}$, respectively. $\mathrm{Gd}$ atoms are indicated by green colours, while $\mathrm{Zn}$ atoms are indicated by blue colours. In Fig. 4a, there are no precipitates found in the $\mathrm{Mg}$ matrix in the as-cast sample. Table 1 lists the composition of $\mathrm{Mg}$ matrix in as-cast state. Compared to solution-treated sample at $520{ }^{\circ} \mathrm{C}$ for $2 \mathrm{~h}, \mathrm{Zn}$ and $\mathrm{Gd}$ contents in as-cast sample are more dilute, and $\mathrm{Gd} / \mathrm{Zn}$ ratio is also low. This composition difference may cause 

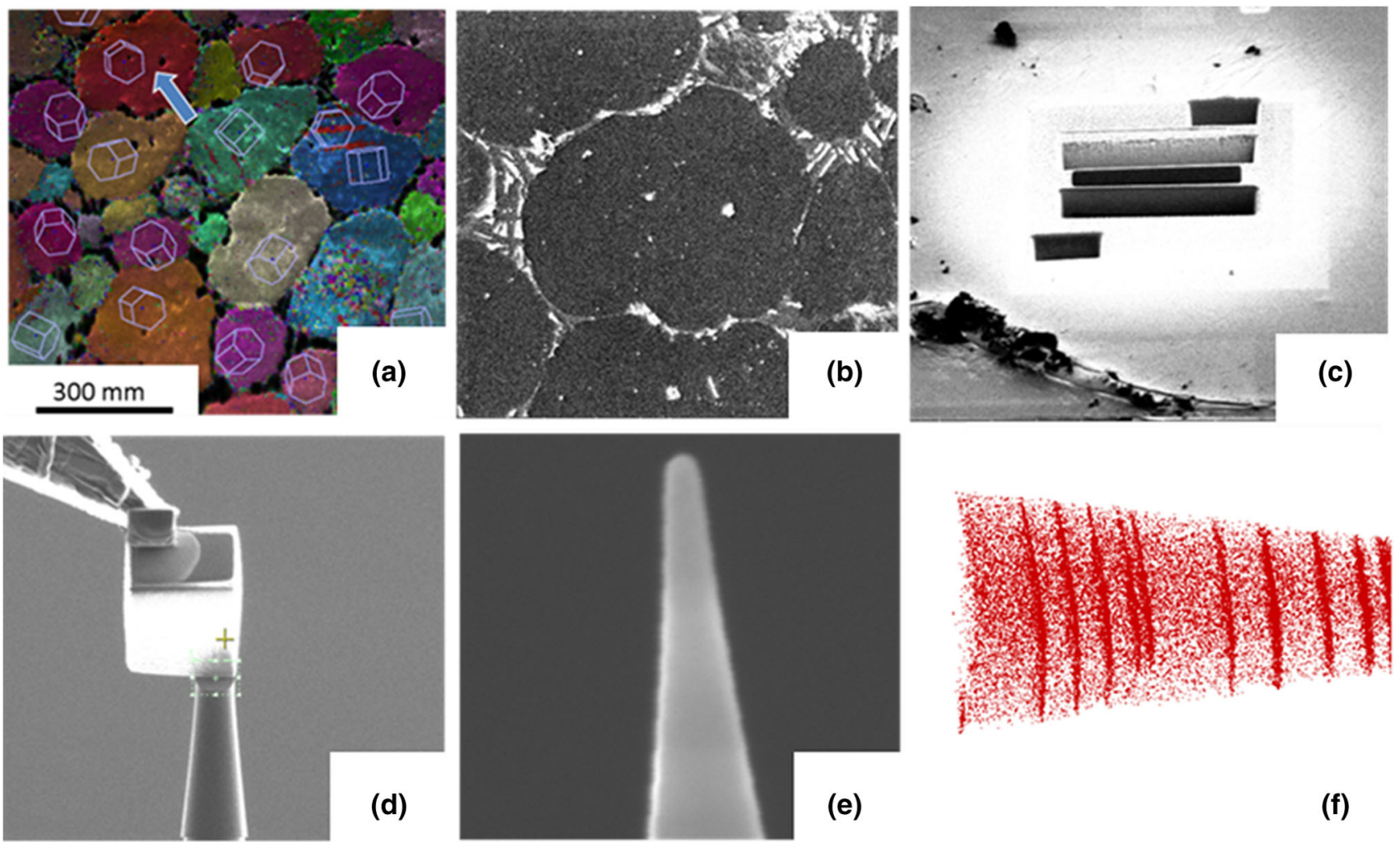

Fig. 3 Preparation procedure of 3DAP sample: a inverse pole figure (normal direction) mapping of $\mathrm{Mg}$ sample by EBSD, b selected grain as indicated in a with arrow, $\mathbf{c}$ cutting with FIB, $\mathbf{d}$ mounting to silicon stage, $\mathbf{e}$ needling, $\mathbf{f}$ test and obtain the result of element distribution

(a)

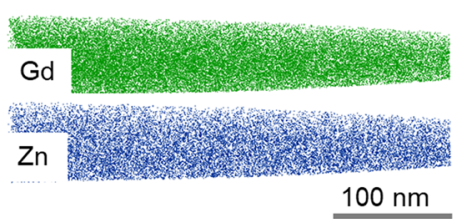

(b)

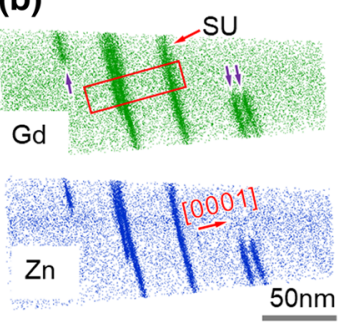

Fig. 4 Element distribution of $\mathrm{Gd}$ and $\mathrm{Zn}$ solute atoms in $\mathrm{Mg}$ matrix for $\mathrm{Mg}-\mathrm{Zn}-\mathrm{Gd}$ alloy: a as-cast sample, $\mathbf{b}$ aged at $280^{\circ} \mathrm{C}$ for $1 \mathrm{~h}$

Table 1 Composition in $\mathrm{Mg}$ matrix before and after solution treatment (at.\%)

\begin{tabular}{llll}
\hline & $\mathrm{Mg}(\%)$ & $\mathrm{Gd}(\%)$ & $\mathrm{Zn}(\%)$ \\
\hline Un-solution & 99.4 & 0.40 & 0.24 \\
Solution & 98.3 & 1.3 & 0.39 \\
\hline
\end{tabular}

different precipitations before and after solution treatment. The precipitation in solution-treated sample is mainly $\gamma^{\prime \prime}$, while the precipitates in as-cast sample are SU $\left(\gamma^{\prime}\right)$ [33]. Therefore, in order to directly study $\mathrm{Zn}-\mathrm{Gd}$ clusters before the precipitation of SU, direct ageing of as-cast sample is investigated in this study.

In Fig. 4b, obvious enrichment of solute atoms is found after ageing. According to 3D distribution of solute atoms, the shape of the enrichment in Fig. $4 \mathrm{~b}$ is confirmed to be planar shape. This kind of enrichment is caused by the precipitation of fcc SU when ageing at $280{ }^{\circ} \mathrm{C}$ for $1 \mathrm{~h} \mathrm{[33].}$ In the SU, they are synchronized with chemical enrichment of $\mathrm{Zn}$ and $\mathrm{Gd}$ according to Fig. 4b. In addition, the $\mathrm{SU}$ is parallel to $(0001)_{\alpha}$ plane, and the needle axis is nearly along $[0001]_{\alpha}$.

A detailed view of rectangular area in Fig. $4 \mathrm{~b}$ is shown in Fig. 5. The pink dots represent $\mathrm{Mg}$ atoms. The spacing of $\mathrm{Mg}$ layers in Fig. $5 \mathrm{a}$ is about $0.5 \mathrm{~nm}$, which is near the lattice parameter $c$ of hcp Mg. In the left side of Fig. 5a, there are two SUs with a spacing of about $2 \mathrm{~nm}$, which is close to $14 \mathrm{H}$ LPSO. The right side of Fig. 5a shows a single SU. From these single SUs, the composition of SU could be determined. Figure $5 b$ shows the concentration profile of $\mathrm{Zn}$ and $\mathrm{Gd}$ in Fig. 5a. $\mathrm{Zn}$ and $\mathrm{Gd}$ atoms are synchronized in the SUs. It is also found that the composition of $\mathrm{SU}$ is $\mathrm{MgGd}_{4-7} \mathrm{Zn}_{3-6}$, which is lower than ideal composition of SU, i.e. $\mathrm{Mg}_{70.8} \mathrm{RE}_{16.7} \mathrm{Zn}_{12.5}$ deduced from perfect LPSO structure from Egusa et al. [5]. However, generally the $\mathrm{Gd} / \mathrm{Zn}$ ratio is larger than 1 and close to $4 / 3$ 
(a)

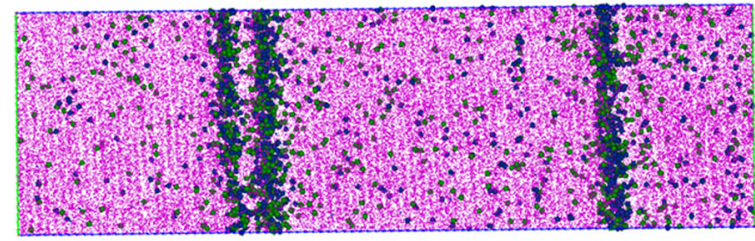

(b)

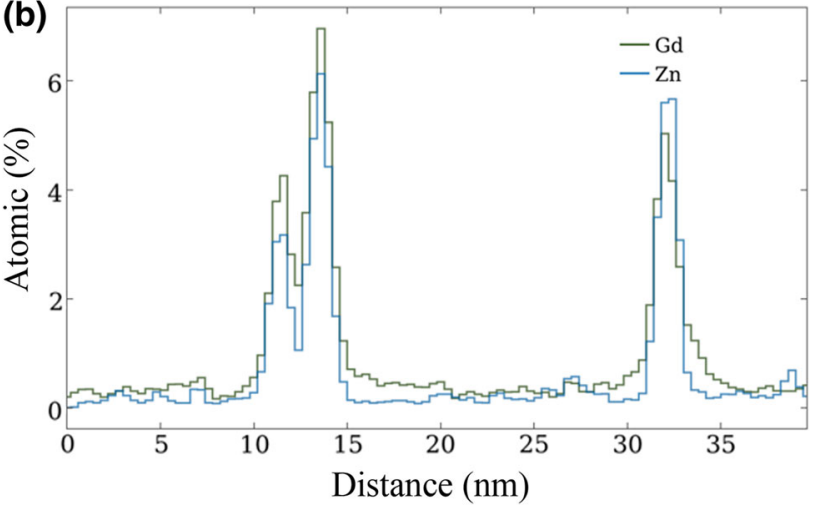

Fig. 5 Enlarged view of rectangular area in Fig. 4b: a element mapping of $\mathrm{Mg}, \mathrm{Zn}$ and $\mathrm{Gd}$, and $\mathrm{Mg}$ atoms is shown by pink dots, b corresponding concentration profile

for $M_{6} \mathrm{RE}_{8}$. Moreover, based on the compositions of the SUs, it could be further confirmed that the precipitates in the present study are SUs here, since the contents of $\mathrm{Zn}$ and Gd of $\gamma^{\prime \prime}$ phase are near 15 at.\% while SU has a lower $\mathrm{Zn}$ and $\mathrm{Gd}$ content [36, 42]. Considering the composition variations in SUs in Fig. 5b, it could be deduced that the solute atoms in SU may be enriched further during ageing. Taking the left two neighbouring SUs in Fig. 5b, for example, the size of SU in left side is smaller than right one according to Fig. 4b, and probably the left SU forms late. Correspondingly, the composition of $\mathrm{Zn}$ and $\mathrm{Gd}$ in left SU is lower than right one.

Since the element distributions at different ageing times have been obtained by 3DAP tomography, the solute clusters within the matrix could be further analysed. Figure 6 shows the evolution of the clusters between $\mathrm{Zn}$ and Gd during ageing. The cluster tendency between $\mathrm{Zn}$ and $\mathrm{Gd}$

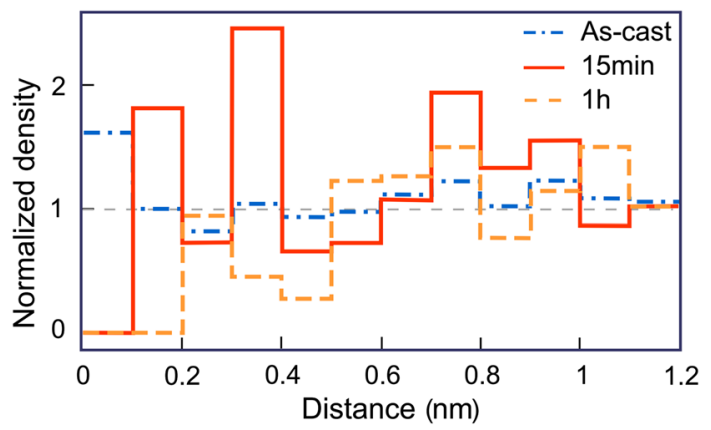

Fig. 6 Radius distribution function between $\mathrm{Zn}$ and $\mathrm{Gd}$ pairs in $\mathrm{Mg}$ matrix for different ageing times in matrix is evaluated by the radial distribution function. For calculating the radial distribution function, the number of Gd atoms in a shell of width $\Delta r=1 \AA$ at distance $r$ with a given atom $\mathrm{Zn}$ is calculated, and then, the number is normalized with average density. For a random distribution, the density should be 1 , and any deviation from 1 will indicate possible cluster or separation tendency. This method is effective for systems containing small clusters [43]. According to Fig. 6, it is found that $\mathrm{Zn}$ and $\mathrm{Gd}$ atoms have the tendency to stay together to be a cluster, because the normalized density is higher at smaller separation distance. At the early stage of ageing for $15 \mathrm{~min}$, the shortest clustering distance between $\mathrm{Zn}$ and $\mathrm{Gd}$ atoms is about $0.2-0.4 \mathrm{~nm}$ according the radial distribution between those atoms, which is close to the lattice parameter of $\mathrm{Mg}$ matrix in base plane $(0.32 \mathrm{~nm})$. Furthermore, a high frequency at the distance of around $0.8-1 \mathrm{~nm}$ is recognized, which may indicate some correlation between clusters. As ageing is prolonged to $1 \mathrm{~h}$, the SUs form, and the cluster tendency between $\mathrm{Zn}$ and $\mathrm{Gd}$ atoms is weakened, which may be attributed to the precipitation of SU and LPSO structure.

According to the first-principle calculation by Kimizuka et al. [44], the binding energy of different atomic pairs in matrix varies at the different nearest neighbour (nn) as listed in Table 2. The different $\mathrm{nn}$ is schematically shown in Fig. 7. For $\mathrm{Zn}-\mathrm{Gd}$ pair, they are preferred at short nn and may correspond to the $0.2-0.4-\mathrm{nm}$ peak in Fig. 6. The near 1.0-nm peak may correspond to the distance between different $\mathrm{L1}_{2}$ clusters after the formation of the SU [45]. Therefore, the solute atoms have the tendency to form $\mathrm{Zn}-$ Gd clusters in the Mg matrix before the formation of SU. Next, the solute enrichment near the interface between SU matrix and $\mathrm{Mg}$ matrix will be studied.

Transformation (growth) fronts in the SUs are observed in Fig. 4b, indicated by double arrows in the figure. A thin slice parallel to $(0001)_{\alpha}$ around the left SU in Fig. $4 \mathrm{~b}$ is taken out and viewed along $[0001]_{\alpha}$ direction as shown in Fig. 8. The transforming SU is clear as shown in Fig. 8b, c, since it is enriched with $\mathrm{Gd}$ and $\mathrm{Zn}$. The [0001] $]_{\alpha}$ zone in Fig. 8a could be found in $\mathrm{Mg}$ atom map according to its symmetry, and this pattern could be used to identify the edge direction of the transformation front. Since the needle axis of 3DAP sample is close to $[0001]_{\alpha}$, the pole of

Table 2 Binding energy between solute atoms in the matrix (eV) [44]

\begin{tabular}{lccc}
\hline & $\mathrm{Zn}-\mathrm{Zn}$ & $\mathrm{Gd}-\mathrm{Gd}$ & $\mathrm{Zn}-\mathrm{Gd}$ \\
\hline $1 \mathrm{nn}$ & 0.004 & 0.022 & -0.077 \\
$1 \mathrm{nn}^{\prime}$ & 0.011 & 0.066 & -0.08 \\
$2 \mathrm{nn}$ & -0.026 & -0.172 & 0.064 \\
$3 \mathrm{nn}$ & 0.0001 & -0.104 & 0.015 \\
\hline
\end{tabular}




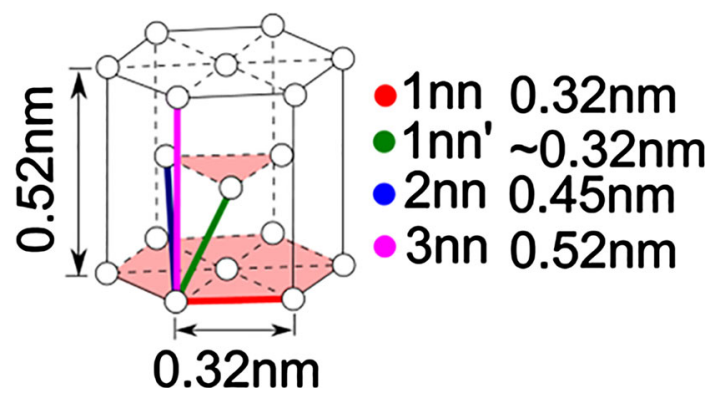

Fig. 7 Interatomic distance for different nearest neighbours in hcp structure [44] (a)



(b)



(c)

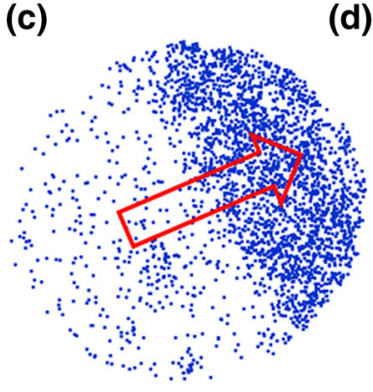

(d)

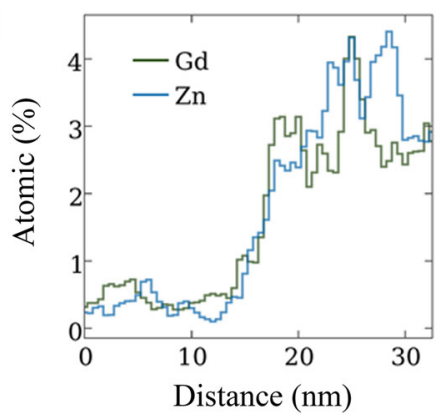

Fig. 8 Transforming front of the SU in the left side in Fig. 4b indicated by double arrow: a $\mathrm{Mg}$ mapping, b $\mathrm{Gd}$ mapping, c $\mathrm{Zn}$ mapping, $\mathbf{d}$ element distribution along the arrow in $\mathbf{c}$. View direction is $[0001]_{\alpha}$

$[0001]_{\alpha}$ can be easily found at the detector event histogram which is due to the aberration evaporation near zone axis $[46,47]$. The superimposition of detector event histogram and stereographic projection is shown in Fig. 9, and the aberration traces are along $\langle 1-100\rangle_{\alpha}$ direction. Therefore, the traces in Fig. 8a are along $\langle 1-100\rangle_{\alpha}$ direction according to Fig. 9. The $\langle 1-100\rangle_{\alpha}$ direction is frequently observed in our case, though the edge of transformation front along $\langle 11-20\rangle_{\alpha}$ direction is also observed, which is consistent with TEM study [48]. The variation in $\mathrm{Zn}$ and Gd normal to the edge of transformation front, i.e. along the arrow direction in Fig. 8c, is shown in Fig. 8d. Gd and $\mathrm{Zn}$ are synchronized along the direction indicated by the arrows. The component of $\mathrm{Zn}$ and $\mathrm{Gd}$ is similar to the left $\mathrm{SU}$ in Fig. 5, which means that the initial formed SU may have lower solute content and will be enriched after further annealing. Nevertheless, the growth of LPSO is

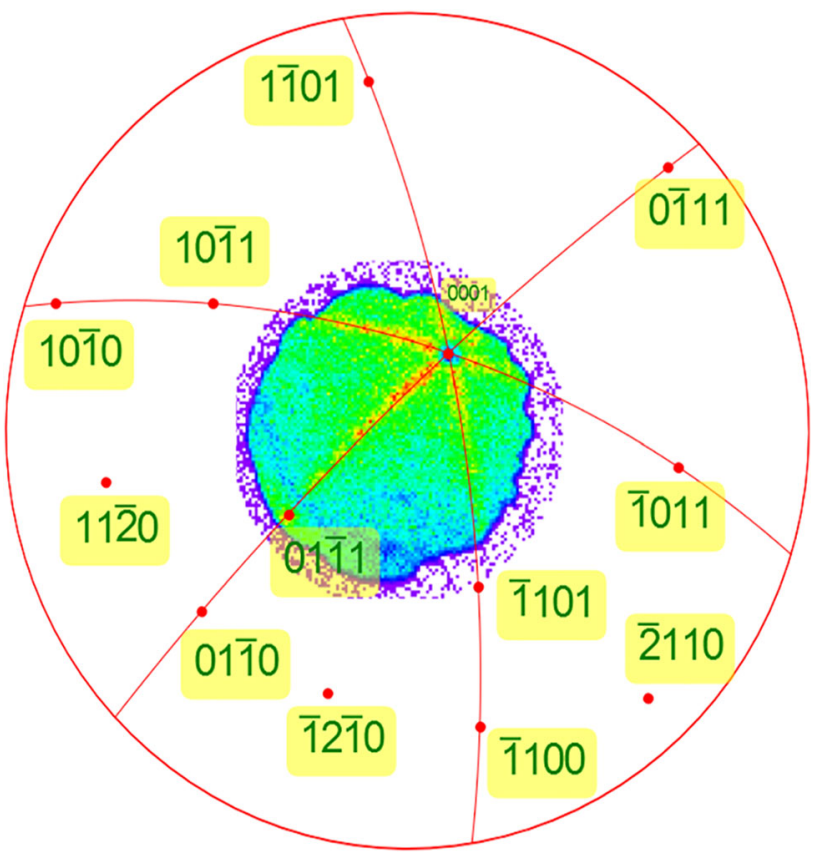

Fig. 9 Superimposition of detector event histogram and stereographic projection of hcp structure

accompanied by the solute enrichment of both $\mathrm{Zn}$ and $\mathrm{Gd}$ solute atoms. Moreover, accordingly, there is no segregation of $\mathrm{Zn}$ or $\mathrm{Gd}$ at the transformation front.

\section{Conclusions}

The chemical enrichment of solute atoms in Mg matrix and SU/LPSO structure in $\mathrm{Mg}_{97} \mathrm{Zn}_{1} \mathrm{Gd}_{2}$ has been studied by 3DAP for different ageing times.

(1) According to the radial distribution between $\mathrm{Zn}$ and $\mathrm{Gd}$ in $\mathrm{Mg}$ matrix, solute atoms $\mathrm{Zn}$ and $\mathrm{Gd}$ tend to be clustered at the first nearest neighbour and decrease with ageing time due to precipitation. The cluster behaviour could be rationalized by the binding energy between $\mathrm{Zn}$ and $\mathrm{Gd}$ atoms.

(2) The fcc SU is synchronized with chemical enrichment of $\mathrm{Zn}$ and $\mathrm{Gd}$. The composition of $\mathrm{SU}$ is determined to be $\mathrm{MgGd}_{4-7} \mathrm{Zn}_{3-6}$ and lower than theoretical composition. The content of $\mathrm{Zn}$ and $\mathrm{Gd}$ in SU enriches during ageing.

(3) The complementary crystallography information at transformation fronts has been obtained from 3DAP data. The edge of transformation front in a SU is often along a low indexed direction, such as $\langle 1-100\rangle_{\alpha}$, according to the aberration evaporation near $[0001]_{\alpha}$ zone axis. The solute atoms $\mathrm{Zn}$ and $\mathrm{Gd}$ are also synchronized across the front of the transformation in this system, and the growth of 
LPSO structure is accompanied by the solute enrichment of both $\mathrm{Zn}$ and $\mathrm{Gd}$ solute atoms. Furthermore, there is no segregation of $\mathrm{Zn}$ or $\mathrm{Gd}$ at the transformation front.

Acknowledgements This work was supported by a Grant-in-Aid for Scientific Research on Innovative Areas, "Synchronized Long-Period Stacking Ordered Structure", from the Ministry of Education, Culture, Sports, Science and Technology, Japan (No. 23109006), and Fundamental Research Funds for the Central Universities (No. FRFTP-17-003A1). In addition, the organization of this symposium by Prof. R.Z. Wu (Harbin Engineering University) is greatly appreciated.

\section{References}

[1] I. Polmear, D. StJohn, J.-F. Nie, M. Qian (eds.), Light Alloys (Butterworth-Heinemann, Boston, 2017)

[2] Y. Kawamura, K. Hayashi, A. Inoue, T. Masumoto, Mater. Trans. 42, 7 (2001)

[3] Y. Kawamura, T. Kasahara, S. Izumi, M. Yamasaki, Scripta Mater. 55, 5 (2006)

[4] K. Hagihara, N. Yokotani, Y. Umakoshi, Intermetallics 18, 2 (2010)

[5] X. Shao, Z. Yang, X. Ma, Acta Mater. 58, 14 (2010)

[6] M. Yamasaki, T. Anan, S. Yoshimoto, Y. Kawamura, Scr. Mater. 53, 7 (2005)

[7] M. Yamasaki, K. Hashimoto, K. Hagihara, Y. Kawamura, Acta Mater. 59(9), 3646 (2011)

[8] X. Zeng, Y. Wu, L. Peng, D. Lin, W. Ding, Y. Peng, Acta Metall. Sin. 46, 9 (2010). (in Chinese)

[9] J.H. Zhang, L. Zhang, Z. Leng, S.J. Liu, R.Z. Wu, M.L. Zhang, Scr. Mater. 68, 9 (2013)

[10] Y. Kawamura, M. Yamasaki, Mater. Trans. 48, 11 (2007)

[11] Q.Q. Jin, X.H. Shao, X.B. Hu, Z.Z. Peng, X.L. Ma, Philos. Mag. 97, 1 (2017)

[12] S.B. Mi, Q.Q. Jin, Scripta Mater. 68, 8 (2013)

[13] H. Yokobayashi, K. Kishida, H. Inui, M. Yamasaki, Y. Kawamura, Acta Mater. 59, 19 (2011)

[14] Z. Luo, S. Zhang, Y. Tang, D. Zhao, J. Alloys Compd. 209, 1 (1994)

[15] C. Liu, Y. Zhu, Q. Luo, B. Liu, Q. Gu, Q. Li, J. Mater. Sci. Technol. 34, 12 (2018)

[16] Y. Xu, D. Xu, X. Shao, E. Han, Acta Metall. Sin. (Engl. Lett.) 26, 3 (2013)

[17] E. Abe, A. Ono, T. Itoi, M. Yamasaki, Y. Kawamura, Philos. Mag. Lett. 91, 10 (2011)

[18] M. Matsuda, S. Ii, Y. Kawamura, Y. Ikuhara, M. Nishida, Mater. Sci. Eng. A 393, 1 (2005)
[19] Y.M. Zhu, M. Weyland, A.J. Morton, K. Oh-Ishi, K. Hono, J.F. Nie, Scr. Mater. 60, 11 (2009)

[20] D. Egusa, E. Abe, Acta Mater. 60, 1 (2013)

[21] J.F. Nie, Y.M. Zhu, A.J. Morton, Metall. Mater. Trans. A 45, 8 (2014)

[22] K. Kishida, H. Yokobayashi, H. Inui, M. Yamasaki, Y. Kawamura, Intermetallics 31, 55-64 (2012)

[23] X.F. Gu, T. Furuhara, L. Chen, P. Yang (2018). arXiv:1805. 07110

[24] S. Kurokawa, A. Yamaguchi, A. Sakai, Mater. Trans. 54, 7 (2013)

[25] H. Kimizuka, S. Kurokawa, A. Yamaguchi, A. Sakai, S. Ogata, Sci. Rep. 4, 6841 (2014)

[26] Y.M. Zhu, A.J. Morton, J.F. Nie, Acta Mater. 60, 19 (2012)

[27] X.F. Gu, T. Furuhara, L. Chen, P. Yang, Scr. Mater. 150, 45 (2018)

[28] H. Okuda, M. Yamasaki, Y. Kawamura, M. Tabuchi, H. Kimizuka, Sci. Rep. 5, 14186 (2015)

[29] H. Okuda, M. Yamasaki, Y. Kawamura, Scr. Mater. 139, 26 (2017)

[30] S. Iikubo, S. Hamamoto, H. Ohtani, Mater. Trans. 54, 5 (2013)

[31] K. Kishida, H. Yokobayashi, H. Inui, Philos. Mag. 93, 21 (2013)

[32] J.K. Kim, L. Jin, S. Sandlöbes, D. Raabe, Sci. Rep. 7, 1 (2017)

[33] S. Matsunaga, Initial Formation Stage of Long Period Stacking Ordered Phase in Mg-Based Ternary Alloys (Graduate School of Engineering, Tohoku University, Sendai, 2015)

[34] D.H. Ping, K. Hono, J.F. Nie, Scr. Mater. 48, 8 (2003)

[35] D.H. Ping, K. Hono, Y. Kawamura, A. Inoue, Philos. Mag. Lett. 82, 10 (2002)

[36] J.F. Nie, K. Oh-ishi, X. Gao, K. Hono, Acta Mater. 56, 20 (2008)

[37] N. Stanford, G. Sha, A. La Fontaine, M.R. Barnett, S.P. Ringer, Metall. Mater. Trans. A 40, 10 (2009)

[38] Q. Liu, Y. Chen, C. Li, J. Gu, Acta Metall. Sin. (Engl. Lett.) 31, 5 (2018)

[39] M. Yamasaki, M. Sasaki, M. Nishijima, K. Hiraga, Y. Kawamura, Acta Mater. 55, 20 (2007)

[40] Y.J. Wu, D.L. Lin, X.Q. Zeng, L.M. Peng, W.J. Ding, J. Mater. Sci. 44, 6 (2009)

[41] K. Saito, A. Yasuhara, K. Hiraga, J. Alloys Compd. 509, 5 (2011)

[42] X.F. Gu, T. Furuhara, T. Kiguchi, T.J. Konno, L. Chen, P. Yang, Scr. Mater. 146, 024504 (2018)

[43] F. De Geuser, W. Lefebvre, D. Blavette, Philos. Mag. Lett. 86, 64 (2006)

[44] H. Kimizuka, S. Ogata, Mater. Res. Lett. 1, 4 (2013)

[45] H. Kimizuka, M. Fronzi, S. Ogata, Scr. Mater. 69, 8 (2013)

[46] B. Gault, M.P. Moody, J.M. Cairney, S.P. Ringer, Mater. Today 15, 9 (2012)

[47] B. Gault, M.P. Moody, J.M. Cairney, S.P. Ringer, Atom Probe Microscopy (Springer, New York, 2012)

[48] K. Sato, S. Tashiro, S. Matsunaga, Y. Yamaguchi, T. Kiguchi, T.J. Konno, Philos. Mag. 98, 21 (2018) 